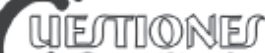 Constitucionales
}

Revista Mexicana de Derecho Constitucional

Núm. 25, julio-diciembre 2011

\section{LOS DERECHOS HUMANOS: NATURALEZA, DENOMINACIÓN Y CARACTERÍSTICAS}

\author{
THE HUMAN RIGHTS: NATURE, DENOMINATION \\ AND CHARACTERISTICS
}

\author{
Jorge CARPIZO*
}

RESUMEN: La idea principal que nos transmite el autor en este artículo consiste en que la base de los derechos humanos es la dignidad de la persona, la cual está por encima de consideraciones positivistas $\mathrm{y}$, debido a ella, nadie puede legítimamente impedir a otro el goce de sus derechos. Esta idea está robustecida con dos nociones cuidadosamente elaboradas por el autor. Por una parte, la de dignidad humana, que es lo que singulariza a la persona de otros seres vivos debido a su razón, voluntad, libertad, igualdad e historicidad y, por otra, la de los derechos humanos que son el conjunto de atribuciones reconocidas por instrumentos jurídicos para hacer efectiva la idea de dignidad de todas las personas, lo que permite una existencia humana desde diversos ámbitos relacionados entre sí, como son el individual, social, político, económico y cultural.

Palabras clave: derechos humanos, dignidad humana, armonización de derechos, derechos fundamentales.
ABSTRACT: The main idea the author conveys in this paper is considering dignity of the person as the basis of human rights which is above of positive considerations and because of it no one can legitimately impede to others from enjoyment of their rights. This idea is strengthened with two notions carefully made by the author. On the one hand, the human dignity, which is what singles out the person from other living beings due to their reason, will, freedom, equality and historicity, and by the other hand, the human rights which are a whole of attributions recognized by legal instruments to enforce the idea of dignity of all persons, allowing a human existence from various interrelated fields, such as the individual, social, political, economic and cultural.

Descriptors: human rights, human dignity, Harmonization of rights, fundamental rights.

* Investigador emérito de la Universidad Nacional Autónoma de México, de la cual fue rector, adscrito al Instituto de Investigaciones Jurídicas, donde se desempeñó como director; presidente del Instituto Iberoamericano de Derecho Constitucional. 


\section{INTRODUCCIÓN}

1. Sobre la naturaleza de los derechos humanos existen dos perspectivas principales desde hace muchos siglos. Una sostiene que los derechos humanos son aquellos que el Estado otorga en su orden jurídico. La segunda manifiesta que el Estado sólo los reconoce y los garantiza en alguna medida. En la primera perspectiva se encuentran diversas concepciones o matices positivistas; en la segunda, la de derecho natural, las escuelas son muy diversas unas de otras.

En conceptos jurídicos, en el positivismo se expresa que es el orden jurídico el que otorga la calidad de persona al ser humano; es decir, persona es una categoría jurídica que se puede conceder o no, o de la cual se puede excluir a un ser humano o a un grupo de ellos, como pueden ser los esclavos, los extranjeros, las mujeres, por razones de raza o por preferencias sexuales.

En cambio, en las concepciones de derecho natural el ser humano, por el solo hecho de existir, es persona y posee derechos y obligaciones; o sea, el Estado no puede desconocer esta situación, lo único que realiza es el reconocimiento de este hecho, y a partir de él se garantizan diversas series de derechos, a los cuales en la actualidad se les denomina derechos humanos, denominación sobre la que reflexiono más adelante.

2. Las concepciones de derecho natural coinciden entonces en este tronco común de pensamiento y a partir de él toman derroteros muy diversos. Por ejemplo, algunos escritores piensan que la persona tiene una dignidad intrínseca por el hecho de estar en relación directa con lo absoluto. ${ }^{1}$ Otros, entre los que me incluyo, consideramos que no es correcto plantear el problema en esta forma, sino que la base de los derechos humanos se encuentra en la dignidad de la persona, y nadie puede legítimamente impedir a otro el goce de esos derechos. El hombre sólo puede realizarse dentro de la comunidad social, y esta comunidad no tiene otro fin que servir a la persona. El fin de la comunidad es la realización de una obra en común, ${ }^{2}$ y ésta consiste en que cada hombre viva como persona; es decir, con dignidad humana, concepto que examino en este ensayo.

1 Maritain, Jacques, Les Droits de l'Homme et la Loi Naturelle, Nueva York, Editions de la Maison Française, 1942, pp. 14 y 15.

2 Ibidem, pp. 31 y 32. 
Los derechos humanos constituyen mínimos de existencia, y al saberse que serán respetados y promovidos, la persona se moviliza con libertad para lograr vivir con dignidad.

3. La concepción del derecho natural está íntimamente ligada a la de los derechos humanos, la cual en su evolución ha recorrido los más diversos matices. Recuerdo un solo ejemplo: Hesíodo reconoció la existencia de normas de origen divino, y pensó que la labor de los hombres consistía en descubrir ese derecho divino para hacer su propio derecho, el cual debería estar inspirado en dike (la justicia). ${ }^{3}$

4. Considero que encima del derecho positivo sí existe una serie de principios, cuyo fundamento es la noción de dignidad humana, principio que se ha reconocido internacionalmente y que es parte esencial de nuestro acervo cultural. Principio universal porque la historia de los pueblos coincide en su lucha por hacerlo objetivo. La dignidad de la persona como principio superior que ningún ordenamiento jurídico puede desconocer.

5. Entonces, reitero, el fundamento de los derechos humanos se encuentra en la noción de la dignidad humana, motivo por el cual me propongo examinar qué es ésta y cuáles son sus alcances conceptuales.

En la concepción del derecho natural se encuentran nociones que implícitamente están relacionadas con la idea de la dignidad humana desde la Grecia clásica.

\section{LA DIGNIDAD HUMANA}

6. Ese humanismo clásico tuvo un nuevo amanecer en el humanismo renacentista de Giovanni Pico della Mirandola y su "Discurso sobre la dignidad del hombre", a pesar de que su pensamiento se encuentra encuadrado en una concepción religiosa.

Para Pico della Mirandola, Dios concedió al hombre la facultad de construir su destino mediante su libertad; el hombre decide si desea parecerse a una planta o a una bestia, o si, por el contrario, por medio de su raciocinio va a convertirse en un ángel o en un hijo de Dios. El hombre debe cuidar este don — la libre elección — con responsabilidad.

3 Véase Verdross, Alfred, La filosofía del derecho del mundo occidental, México, UNAM-Centro de Estudios Filosóficos, 1962, pp. 433. 
El hombre a su libertad aúna voluntad, inteligencia, deseo de aprender, búsqueda de la verdad y el saber numerar, que no es el arte del cómputo sino de la aritmética divina en la concepción de Platón y Aristóteles.

Así, en ejercicio de su libertad, dispone, y al hacerlo corre riesgos; su dignidad es, en esencia, libertad para decidir. ${ }^{4}$

7. En los aspectos anteriores se ha insistido una y otra vez; diversos autores coinciden en que la dignidad humana se caracteriza por la razón y la libertad que la persona posee, ${ }^{5}$ por la racionalidad humana que le permite tomar decisiones deliberadas, por la superioridad de la persona sobre todos los demás seres y por la pura intelectualidad, entendida como la capacidad de comprensión directa de las cosas, incluso de las espirituales, ${ }^{6}$ por estar el hombre dotado de inteligencia y libertad, por ser distinto y superior a todo lo creado. ${ }^{7}$

8. Humberto Nogueira Alcalá ofrece una definición clara, que es fácil de entender:

La dignidad de la persona es el rasgo distintivo de los seres humanos respecto de los seres vivos, la que constituye a la persona como un fin en sí mismo, impidiendo que sea considerada un instrumento o medio para otro fin, además de dotarlo de capacidad de autodeterminación y de realización del libre desarrollo de la personalidad. ${ }^{8}$

De la dignidad de la persona humana irradia la libertad y la igualdad como principios básicos que se van a concretar en derechos humanos. Germán J. Bidart Campos señala que, asimismo, del concepto de dignidad derivan los derechos personalísimos, como los derechos a la vida, a la integridad

4 Pico della Mirandola, Giovanni, Discurso sobre la dignidad del hombre, México, UNAM, 2009, pp. 15-18, 45-47 y 50.

5 Peces-Barba Martínez, Gregorio, Derechos fundamentales, Madrid, Latino Universitaria, 1980, p. 49, aunque, quizás, esta formulación o su énfasis no es el mismo en su obra Curso de derechos fundamentales. teoría general, con la colaboración de Rafael de Asís Roig, Carlos R. Fernández Liesa y Ángel Llamas Cascón, Madrid, Universidad Carlos III-Boletín Oficial del Estado, 1995, pp. 104, 105 y 108-110.

6 Sánchez de la Torre, Ángel, Teoría y experiencia de los derechos humanos, Madrid, Gregorio del Toro-Editor, 1968, p. 25.

7 González Pérez, Jesús, La dignidad de la persona, Madrid, Civitas, 1986, p. 112.

8 Nogueira Alcalá, Humberto, La interpretación constitucional de los derechos humanos, Lima, Perú, Ediciones Legales, 2009, pp. 11 y 14. 
física y psíquica, al honor, a la privacidad, al nombre, a la propia imagen, al estado civil, y el propio derecho a la dignidad personal. ${ }^{9}$

9. La concepción de la dignidad humana no conduce a un individualismo; al contrario, reconoce el valor de la comunidad: yo exijo respeto a mi dignidad frente al Estado, grupos y otras personas que poseen igual dignidad. Soy consciente de todo lo que debo a los otros y cuanto los necesito. Me comunico mediante un idioma que aprendí de mis semejantes, así como mil otros aspectos y pensamientos que configuran mi personalidad, y cada uno de los demás tiene su propia dignidad, que debo respetar. Cada persona es un universo que convive con terceros universos, cuya esencia es la misma que la suya: la dignidad humana. En el seno de la comunidad tengo el derecho a ser yo mismo, a mi independencia y a mi individualidad. ${ }^{10}$

Los derechos basados en la dignidad humana no convierten al hombre en una "mónada", según expresión de Marx, sino destacan su calidad de persona, impulsan al hombre a superarse y a lograr, dentro del marco social, su realización como ser humano. Esta realización no la consigue en forma aislada y egoísta, sino en la sociedad y persiguiendo finalidades no sólo dentro de las fronteras nacionales, sino con una perspectiva más amplia: la realización propia, entre la de millones de destinos, como hombre y ciudadano de un mundo.

10. La base y esencia de los derechos humanos se encuentra en la dignidad humana y ésta carecería de sentido sin la existencia de aquéllos. En realidad, forman una unidad indestructible.

Entonces, ¿qué es realmente la dignidad humana? Es el reconocimiento del especial valor que tiene el individuo en el universo. ¿Y en qué consiste ese especial valor?

En que la vida es valiosa, porque sin vida nada existe, pero vida también la poseen los animales y las plantas. Lo que diferencia al hombre de éstos es la razón, es su facultad de razonar. De la razón se deriva la capacidad de decisión, lo que necesariamente implica un margen de libertad, y que frente a él se encuentran muchos hombres y mujeres que poseen idéntica

9 Bidart Campos, Germán J., Teoría general de los derechos humanos, México, UNAM-Instituto de Investigaciones Jurídicas, 1993, p. 79.

10 Einstein, Albert, "Como veo el mundo", en Herrendorf, Daniel L. (comp.), Teoría general y política de los derechos humanos, México, Comisión Nacional de Derechos Humanos, 1992, pp. 264 y 265. Ortecho Villena, Víctor Julio, Los derechos fundamentales en el Perú, Lima, Chiclayo, Perú, Editorial Rodhas, 2008, p. 12. 
característica: la razón, por lo cual todos y todas son iguales y merecen el mismo respeto y los mismos derechos.

Del ser racional, único y singular en este mundo, derivan otras características que sólo él posee entre los seres vivos: se apropia de conocimientos acumulados y mejorados por generaciones anteriores, aprende un lenguaje conceptual para comunicarse con sus semejantes, se adueña de la historia que le antecede, tiene la posibilidad de hacer historia, de forjarse una personalidad y de construir su existencia, dentro de la sociedad, con decisiones en ejercicio de su libertad y emanadas de su razón y de su voluntad.

Sólo apunto que el ser humano no es únicamente razón, es un ser complejo con inteligencia emocional, centro de pasiones de la más diversa índole e incluso de irracionalidades que pueden afectar su propia dignidad, como es el caso de la existencia de los fanatismos religiosos.

No obstante, la persona dotada de razón es la que ha construido este mundo y el contexto social, político, económico y cultural en el cual se vive. Ella edifica los rascacielos y los aviones; pero también crea los holocaustos.

La dignidad humana es el reconocimiento de que la persona es algo especial y extraordinario, debido a su racionalidad y a todo lo que ello implica y que he asentado en los párrafos anteriores y, en consecuencia, hay que protegerla y defenderla.

Así, la dignidad humana singulariza y caracteriza a la persona de los otros seres vivos, debido a su razón, voluntad, libertad, igualdad e historicidad.

11. La primera vez que se reconoció en un documento jurídico el concepto de dignidad humana fue en el ámbito internacional, en la Carta de las Naciones Unidas de 1945:

Nosotros los pueblos

de las Naciones Unidas

resueltos

$\cdots$

a reafirmar la fe en los derechos fundamentales del hombre, en la dignidad y el valor de la persona humana, en la igualdad de derechos de hombres y mujeres...

12. La Declaración Americana de los Derechos y Deberes del Hombre de 1948 en su preámbulo manifiesta que: "Todos los hombres nacen libres e iguales en dignidad y derechos y, dotados como están por naturaleza de razón y conciencia, deben conducirse fraternalmente los unos con los otros". 
Meses después de esa Declaración se aprobó la Declaración Universal de los Derechos Humanos en 1948, cuyo preámbulo se refiere en dos ocasiones a la idea de la dignidad humana:

Considerando que la libertad, la justicia y la paz en el mundo tienen por base el reconocimiento de la dignidad intrínseca y de los derechos iguales e inalienables de todos los miembros de la familia humana,

Considerando que los pueblos de las Naciones Unidas han reafirmado en la Carta su fe en los derechos fundamentales del hombre, en la dignidad y el valor de la persona humana...

Los artículos 1, 22 y 23 de dicha Declaración se refieren expresamente a la dignidad humana: "Todos los seres humanos nacen libres e iguales en dignidad y derechos y dotados como están de razón y conciencia deben comportarse fraternalmente los unos con los otros" (artículo 1o.).

13. El Pacto Internacional de Derechos Civiles y Políticos de Naciones Unidas de 1966 reitera las mismas ideas en su preámbulo: “...Reconociendo que estos derechos se derivan de la dignidad inherente a la persona humana...", conceptos que se vuelven a manifestar, como es natural, en el Pacto Internacional de Derechos Económicos, Sociales y Culturales de ese mismo año.

14. En el ámbito, la primera Constitución que incorporó el concepto de dignidad humana fue la Ley Fundamental de Bonn de 1949 en su artículo 10.: "La dignidad del hombre es intangible. Los poderes públicos están obligados a respetarla y protegerla". De acuerdo con el artículo 79.1, el mencionado artículo 1o. no es susceptible de reforma constitucional.

El artículo 1o. de la Constitución de Portugal de 1976 dispone que: "Portugal es una República soberana, basada en la dignidad de la persona humana y en la voluntad popular y empeñada en la construcción de una sociedad libre, justa y solidaria".

El artículo 10.1 de la Constitución Española de 1978 dice: "La dignidad de la persona, los derechos inviolables que le son inherentes, el libre desarrollo de la personalidad, el respeto a la ley y a los derechos de los demás son fundamento del orden político y de la paz social".

Esta gran corriente se ha introducido en las Constituciones de América Latina a partir de la década de los años ochenta. Por ejemplo: 
El artículo 1o. de la Constitución de Brasil de 1988 indica que el país “...se constituye en un Estado democrático de derecho y tiene como fundamentos: ...III. la dignidad de la persona humana...”.

El artículo 1o. de la Constitución de Colombia de 1991 expresa: "Colombia es un Estado social de derecho...fundada en el respeto de la dignidad humana...".

El artículo 1o., párrafo 1, de la Constitución de Chile de 1980 dispone: "Las personas nacen libres e iguales en dignidad y derechos...".

El artículo 1o., párrafo 2, de la Constitución de Paraguay de 1992 dice: "La República de Paraguay adopta para su gobierno la democracia representativa, participativa y pluralista, fundada en el reconocimiento de la dignidad humana".

El artículo 1o. de la Constitución de Perú señala: "La defensa de la persona humana y el respeto de su dignidad son el fin supremo de la sociedad y del Estado".

15. La Constitución mexicana no contiene una declaración tan clara y rotunda sobre la dignidad humana como las contenidas en las Constituciones latinoamericanas mencionadas. No obstante, en varios artículos se refiere a ella, y en otros a conceptos muy cercanos.

El artículo 3o., II, c, indica los criterios que orientan a la educación: "Contribuirá a la mejor convivencia humana, tanto por los elementos que aporte a fin de robustecer en el educando, junto con el aprecio para la dignidad de la persona y la integridad de la familia..." (Reforma de 1946).

El artículo 25, párrafo 1, dispone: "Corresponde al Estado la rectoría del desarrollo nacional... y que, mediante el fomento del crecimiento económico y el empleo de una más justa distribución del ingreso y la riqueza, permita el pleno ejercicio de la libertad y la dignidad de los individuos, grupos y clases sociales..." (reforma de 1983).

El artículo 1o., párrafo 3, indica: "Queda prohibida toda discriminación motivada por... o cualquier otra que atente contra la dignidad humana..." (Reforma de 2001).

Muy relacionado con la idea de la dignidad humana, encontramos en la Constitución otras expresiones: la dignidad e integridad de las mujeres indígenas (artículo 2o., II); el respeto a la dignidad de la niñez y el ejercicio pleno de sus derechos (artículo 4o., párrafo 7).

16. También las cortes y tribunales constitucionales se refieren a la dignidad humana. Por ejemplo: la jurisprudencia de la Corte Constitucional de 
Alemania con frecuencia, alude a la dignidad humana en sus resoluciones. $\mathrm{Al}$ respecto se puede citar

...Las fórmulas generales, como la que prevé que los seres humanos no pueden ser degradados al ser tratados por el poder estatal como un simple objeto establecen las directrices que sirven para determinar los casos en los que se da una violación de la dignidad humana. No pocas veces el ser humano se vuelve un simple objeto, no sólo por las circunstancias y del desarrollo social, sino también del derecho, en la medida en que debe adherirse a éste sin que se tomen en cuenta sus intereses. La violación de la dignidad humana no se da por esta sola razón. Se debe añadir el hecho de que la persona haya sido sometida a un trato que cuestiona principalmente su calidad de sujeto, o que en el tratamiento dado en un caso concreto exista una desvalorización arbitraria de la dignidad humana. El trato que afecta la dignidad humana, otorgado por el poder público al ser humano en cumplimiento de la ley, debe ser considerado como una minusvaloración de las garantías de que goza el ser humano por virtud de ser persona, y en ese sentido tiene también el carácter de un "trato abyecto"."

El Tribunal Constitucional español sostiene que los valores constitucionales que otorgan legitimidad

al límite que la inembargabilidad impone al derecho del acreedor a que se cumpla la sentencia firme que le reconoce el crédito se encuentran en el respeto a la dignidad humana, configurado como el primero de los fundamentos del orden político y de la paz social en el artículo 10.1, a cuyo fin resulta razonable y congruente crear una esfera patrimonial intangible a la acción ejecutiva de los acreedores que coadyuve a que el deudor pueda mantener la posibilidad de una existencia digna. ${ }^{12}$

El Tribunal Constitucional peruano ha señalado que la dignidad de la persona humana es el valor superior del ordenamiento y, en consecuencia, el presupuesto ontológico de todos los derechos fundamentales, incluyendo,

11 Sentencia de la Segunda Sala, del 15 de diciembre de 1970, -2BvF1/69, 2BvR629/68 y 308/69, en Jurisprudencia del Tribunal Constitucional Alemán. Extractos de las sentencias más relevantes compiladas por Jürgen Schwabe, México, Konrad Adenauer Stiftung, Programa Estado de Derecho para Latinoamérica, 2009, pp. 53 y 54.

12 Sentencia del TC español 113/1989 del 22 de junio, en el fundamento jurídico 3. Véase http://www.legalsolo.com/ShowSentencia.do? sentenciald=STC1989-113\&senten ciaType $=$ Sentencia\&text $=S T C+23 \% 2 F 2008$. 
desde luego, los de carácter económico, en virtud de que la persona no puede ser un medio "para alcanzar una economía estable sino, por el contrario, debe ser la que auspicie la consecución de un fin superior para el Estado y la sociedad; a saber, la consolidación de la dignidad del hombre". ${ }^{13}$

17. En México, la jurisprudencia de la SCJN aún no contiene una alusión directa al concepto de dignidad humana, aunque se le puede percibir en algunas tesis. ${ }^{14}$

18. El concepto de dignidad humana ha adquirido carácter jurídico: a) al ser incorporado como el fundamento de diversos instrumentos internacionales como los citados, y actualmente es claro el valor jurídico de éstos; $b$ ) al hacerlo suyo múltiples Constituciones como la base y el fundamento de todo el orden jurídico, político y social, y c) al ser un elemento esencial y orientador en la interpretación de las sentencias constitucionales.

No obstante, la doctrina se preocupa por formular una definición de aristas cien por ciento jurídicas. Así, Diego Valadés define el concepto de dignidad humana como "la suma de las potestades reconocidas a la persona, que le dan el carácter de integrante de la voluntad general y, por ende, autor último de las decisiones del Estado". ${ }^{15}$

\section{LA DEFINICIÓN DE DERECHOS HUMANOS Y ASPECTOS TERMINOLÓGICOS}

19. Parto de la idea de que la dignidad humana, como ya asenté, singulariza y caracteriza a la persona de los otros seres vivos, debido a su razón, voluntad, libertad, igualdad e historicidad, y considero que desde una perspectiva jurídica, la dignidad humana es la base del ordenamiento político, jurídico y social de una comunidad, y se asegura su vigencia mediante la defensa y protección de los derechos humanos de la más diversa naturaleza, reconocidos en la Constitución y en los instrumentos internacionales que

13 Sentencia del TC peruano del 11 de noviembre de 2003, en Rubio Correa, Marcial, La interpretación de la Constitución según el Tribunal Constitucional, Lima, Perú, Pontificia Universidad Católica del Perú, 2005, pp. 146 y 147.

14 Silva Meza, Juan N. y Silva García, Fernando, Derechos fundamentales, México, Porrúa, 2009, pp. 5 у 6.

15 Carpizo, Jorge y Valadés, Diego, Derechos humanos, aborto y eutanasia, Madrid, Dykinson, 2010, p. 141. 
ese Estado ha ratificado. Asimismo, la dignidad humana es el fundamento del derecho internacional de los derechos humanos.

Desde esta óptica, una primera definición de los derechos humanos puede ser: el conjunto de atribuciones reconocidas en los instrumentos internacionales y en las Constituciones para hacer efectiva la idea de la dignidad de todas las personas y, en consecuencia, que puedan conducir una existencia realmente humana desde los ámbitos más diversos, los que se imbrican, como el individual, el social, el político, el económico y el cultural.

20. Los que actualmente se denominan derechos humanos han recibido a través del tiempo diversos nombres. Entre algunos de ellos se pueden mencionar los siguientes: derechos del hombre, garantías individuales o sociales, derechos naturales, derechos innatos, derechos esenciales, libertades públicas, derechos de la persona humana, derechos públicos subjetivos y una denominación que se ha extendido es la de derechos fundamentales, a tal grado que existe una importante corriente doctrinal que se basa en diferenciar éstos de los derechos humanos. Es probable que actualmente esta última corriente sea predominante.

21. Las definiciones de derechos humanos son infinitas. Muchas enfatizan que son aquellos que la persona posee por su propia naturaleza y dignidad, son aquellos que le son inherentes y no son una concesión de la comunidad política; que son los que concretan en cada momento histórico las exigencias de la dignidad, la libertad y la igualdad humanas, los cuales deben ser reconocidos positivamente por el orden jurídico nacional e internacional; que son los que corresponden a la persona por esencia, simultáneamente en su vertiente corpórea, espiritual y social, y que deben ser reconocidos y respetados por todo poder o autoridad y toda norma jurídica positiva, pero que ceden en su ejercicio ante las exigencias del bien común; que son expectativas no previstas con claridad en alguna norma jurídica, incluso se llega a identificarlos con los "derechos morales"; que son aquellos imprescindibles para poder conducir una vida digna y auténticamente humana, y constituyen el elemento fundamental de un Estado constitucional democrático de derecho. ${ }^{16}$

16 Truyol y Serra, Antonio, Los derechos humanos, Madrid, Tecnos, 1984, p. 11; Pérez Luño, Antonio, Los derechos fundamentales, Madrid, Tecnos, 2004, p. 46; Castán Tobeñas, José, Los derechos del hombre, Madrid, Reus, 1976, pp. 13 y 14; Carbonell, Miguel, Los derechos fundamentales en México, México, UNAM-Comisión Nacional de los Derechos Humanos, 2004, p. 8; Orozco Henríquez, J. Jesús y Silva Adaya, Juan, 
22. En cambio, los derechos fundamentales, en el criterio de diversos autores, son aquellos que están recogidos en el texto constitucional y en los tratados internacionales, son los derechos humanos constitucionalizados; que su propia denominación indica la prioridad axiológica y su esencialidad en relación con la persona humana; que son los derechos humanos que se plasman en derecho positivo vigente, son las normas que protegen cualquier aspecto fundamental que afecte el desarrollo integral de la persona en una comunidad de hombres libres y en caso de infracción existe la posibilidad de poner en marcha el aparato coactivo del Estado; que son un sistema de valores objetivos dotados de unidad de sentido con interdependencia normativa, cuyo disfrute efectivo exige garantizar mínimos de bienestar económico para que se pueda participar en la vida comunitaria. ${ }^{17}$

23. En consecuencia, la relación entre derechos humanos y derechos fundamentales sería que los primeros implican un mayor matiz filosófico, guardan una connotación prescriptiva y deontológica, y aún no han sido objeto de recepción en el derecho positivo, mientras que los derechos fundamentales son los derechos y libertades reconocidos y garantizados por el derecho positivo de los Estados, ${ }^{18} \mathrm{y}$, para algunos autores, por el derecho internacional de los derechos humanos.

En esta diferencia insiste Antonio E. Pérez Luño, quien la ejemplifica con inteligencia; afirma que los crímenes del régimen nazi, el apartheid de Sudáfrica o la dictadura de Pinochet, que negaba libertades políticas y sindicales, violaban derechos humanos pero no infringían derechos fundamentales, en cuanto dichas conductas eran acordes con esos órdenes jurídicos nacionales. ${ }^{19}$

24. No obstante, considero que los conceptos de derechos humanos y derechos fundamentales cada día se acercan más y va a llegar el momento

Los derechos humanos de los mexicanos, México, Comisión Nacional de los Derechos Humanos, 2002, pp. 7 y 9.

17 Carbonell, Miguel, op. cit., pp. 8 y 9; Nogueira Alcalá, Humberto, op. cit., p. 17; Peces-Barba M., Gregorio, op. cit., p. 93; Silva Meza, Juan N. y Silva García, Fernando, op. cit., p. 26.

18 Bidart Campos, Germán J., op. cit., pp. 47, 48, 158 y 159.

19 Pérez Luño, Antonio E., "La universalidad de los derechos en la 'L' conmemoración de la Declaración Universal de los Derechos Humanos de Naciones Unidas", en Palomino Manchego, José E. y Remotti Carbonell, José Carlos (coords.), Derechos humanos y Constitución en Iberoamérica (Libro-homenaje a Germán J. Bidart Campos), Lima, Instituto Iberoamericano de Derecho Constitucional-Grijley, 2002, p. 415 
en que se van a identificar o van a ser sinónimos. Es la evolución y precisión de las ideas, pero es más, es el sentido correcto del significado de la dignidad humana. El concepto de derecho fundamental va a correr la suerte de otros, como los de derecho público subjetivo, libertad pública o los que mencioné y que cada día se emplean menos, por las razones siguientes:

a) Los instrumentos internacionales, incluso las primeras declaraciones de derechos humanos, que en ese momento no tenían valor jurídico y que en la actualidad sí lo tienen, se refieren a derechos humanos y cada día los precisan más, e incluso varios de esos instrumentos los garantizan jurisdiccionalmente. Se refieren a derechos humanos y cualquier matiz deontológico va desapareciendo. Son instrumentos jurídicos, son parte del derecho internacional de los derechos humanos.

b) Los agudos ejemplos de Pérez Luño, que a primera vista pueden impresionar, no se sostienen, debido a que esas discriminaciones y crímenes sí violaban, aun en su concepción, derechos fundamentales y normas jurídicas, porque violaban el jus cogens, los principios internacionales reconocidos que obligan a todos los países, incluso si no los han aceptado, y la Declaración Universal de los Derechos Humanos, y en el caso de Chile además se violaba la Declaración Americana de los Derechos y Deberes del Hombre y el Pacto de San José; tan es así, que los criminales nazis fueron juzgados y condenados por los delitos que cometieron, y que en ese orden jurídico no eran tales, y eso que el derecho internacional de los derechos humanos aún se encontraba en gestación.

Los regímenes del apartheid y la dictadura de Pinochet, y los ejemplos se pueden multiplicar, cambiaron radicalmente no por voluntad propia, sino por la oposición interna, pero también por las sanciones que estableció la ONU aplicando el derecho internacional, y al aislamiento internacional a que dichos regímenes fueron sometidos. Las sanciones impuestas a esos regímenes, más allá de cualquier consideración moral, ética, de derechos morales, filosófica o deontológica, fueron consecuencia de la violación del derecho internacional de los derechos humanos y el jus cogens. El orden jurídico internacional actuó en forma parecida a cualquier orden jurídico interno.

c) Por la corriente constitucional que otorga a los tratados internacionales, y en especial a los de derechos humanos, jerarquía superior a la propia Constitución, el mismo nivel normativo que ésta o los sitúa por encima de las leyes secundarias del país. En consecuencia, los derechos humanos 
contenidos y protegidos en esos tratados, convenios, convenciones o pactos son normas jurídicas en el orden interno y aquellos se refieren generalmente a derechos humanos.

d) Las Constituciones más recientes de Europa se refieren a derechos fundamentales, libertades y derechos, pero también varias de ellas apuntan a los derechos humanos como sinónimo de los dos conceptos anteriores. Es una corriente que va tomando fuerza. Así:

El artículo 18 de la Constitución de Lituania de 1992 expresa que los derechos humanos y las libertades son innatos.

El preámbulo de la Constitución de la República Checa de 1993 dice que el Estado está fundado en el respeto a los derechos humanos.

El artículo 17.2 de la Constitución de Rusia de 1993 manifiesta: "Los derechos humanos fundamentales y las libertades son inalienables y pertenecen a todos desde el día de su nacimiento".

El preámbulo de la Constitución de Polonia de 1997 se refiere a las amargas experiencias de cuando las libertades fundamentales y los derechos humanos fueron violados en su territorio.

La Constitución de Macedonia, en los artículos 10, 11, 12 y 41, menciona a los derechos humanos.

e) En América Latina también comienza esta tendencia. El título II de la Constitución de Guatemala de 1985 se intitula "Derechos Humanos".

El título III de la Constitución de Venezuela de 1999 recibe por nombre: "De los derechos humanos y garantías, y de los deberes".

25. La Constitución mexicana incorporó el concepto de derechos humanos por primera vez en 1992 al ordenar la creación de organismos de protección de los derechos humanos (ombudsman).

Con posterioridad, los artículos 2o., II, y VIII, y 21, párrafo 9, se refieren expresamente a los derechos humanos.

La Constitución mexicana fue reformada el 10 de junio de 2011 en diez artículos, en lo que se llamó "el paquete de los derechos humanos". El título del capítulo primero del título del mismo numeral pasó a denominarse De los Derechos Humanos y sus Garantías, con lo cual nuestra Constitución aceptó plenamente la corriente que privilegia la designación de los derechos humanos, con lo que concuerdo de manera plena.

Además, se incorporó la expresión de derechos humanos en el artículo 3o. (la educación habrá de fomentarlos); artículo 15 (prohibición de celebrar tratados internacionales en los que se alteren los reconocidos por la 
Constitución y por los instrumentos internacionales ratificados); artículo 18 (como base de la organización del sistema penitenciario); artículo 33 (goce de ellos por parte de los extranjeros); artículo 89, X (como uno de los principios de la política exterior del país).

En la actualidad, en el derecho constitucional mexicano la única acepción correcta es la de derechos humanos, corriente a la que más países se adhieren conforme transcurre el tiempo.

En las naciones que aún no se suman a esta corriente incontenible, el término de derechos humanos es sinónimo de derechos fundamentales y de todos los otros conceptos que las Constituciones suelen utilizar como equivalentes del segundo. Las diferencias entre ellos, que tradicionalmente se han destacado, ya no son sostenibles, debido a: la evolución del derecho internacional de los derechos humanos, el constitucionalismo internacionalizado y las nuevas tendencias del derecho constitucional; el fundamento y base tanto de unos como de otros, aun si no se admite su identificación, es la misma: la dignidad humana.

\section{SUS CARACTERÍSTICAS}

26. Los derechos humanos revisten características que los singularizan; éstas son:
A. Universalidad.
B. Historicidad.
C. Progresividad.
D. Aspecto protector.
E. Indivisibilidad, y
F. Eficacia directa.

27. Digamos unas palabras en relación con cada una de estas características.

A. La universalidad significa que todo ser humano posee una serie de derechos con independencia del país en que haya nacido o habite. Es el sentido de la Declaración Universal de Derechos Humanos y de los pactos de la ONU, de 1966.

La universalidad hace énfasis en que la cuestión de los derechos humanos no es sólo un asunto de cada Estado, sino de la comunidad internacional. 
El Estado tiene la facultad de plasmar cada derecho en su Constitución en la forma que considere más conveniente, pero sin violentar las declaraciones e instrumentos internacionales que ha ratificado ni el jus cogens. Por esta razón, las declaraciones de derechos humanos en las nuevas Constituciones o en sus reformas son más parecidas entre sí.

Las características de los derechos humanos se ensamblan unas con las otras para formar una unidad; no son partes de un todo, sino que son como la sangre, que es única pero compuesta de múltiples elementos.

La universalidad, a su vez, no implica uniformidad, debido a que el Constituyente no puede descuidar factores extrajurídicos como son, entre otros: la evolución política, la cultura, la idiosincrasia, las características y particularidades de esa nación; o sea, existe un "margen de apreciación nacional". ${ }^{20}$

La Declaración y Programa de Acción de Viena de 1993 sostiene que la comunidad internacional "debe tratar los derechos humanos en forma global y de manera justa y equitativa", en virtud de que, en principio, ningún Estado puede negar a un ser humano su disfrute en razón de su "universalidad, objetividad y no selectividad del examen de las cuestiones de derechos humanos". ${ }^{21}$

En otras palabras, como bien expresa Pérez Luño,

...sin el atributo de la universalidad nos podemos encontrar con derechos de los grupos, de las etnias, de los estamentos, de entes colectivos más o menos numerosos, pero no con derechos humanos... la titularidad de los derechos, enunciados como derechos humanos, no va a estar restringida a determinadas personas o grupos privilegiados, sino que va a ser reconocida como un atributo básico inherente a todos los hombres, por el mero hecho de su nacimiento.

Para él, en consecuencia, los derechos humanos o son universales o no son tales. ${ }^{22}$

20 Hesse, Conrado, "Significado de los derechos fundamentales", Benda, Maihofer, Vogel, Hesse, Heyde, Manual de derecho constitucional, Madrid, Marcial Pons, 2001, p. 85.

21 Sagüés, Néstor P., "La interpretación de los derechos humanos en las jurisdicciones nacional e internacional", en Palomino Manchego, José E., y Remotti Carbonell, José Carlos (coords.), Derechos humanos y Constitución en Iberoamérica (Libro-Homenaje a Germán J. Bidart Campos), Lima, Instituto Iberoamericano de Derecho ConstitucionalGrijley, 2002, p. 39.

22 Pérez Luño, Antonio E., op. cit., p. 417. En este ensayo el autor realiza un buen recuento de las principales críticas que ha recibido la característica de universalidad y las 
René Cassin, uno de los grandes promotores y redactores de la Declaración Universal de Derechos Humanos, señaló, en forma bella, el sentido universal de estos derechos: se aplican a todos los hombres de todos los países, razas, religiones, sexos y regímenes políticos. La Declaración iba a ser denominada "internacional", pero la Asamblea General de la ONU la proclamó "Universal" para dejar claro que la persona es miembro directo de la sociedad humana y sujeto directo del derecho internacional. Claro que es ciudadano de su país, pero también del mundo, en virtud de la protección que éste debe otorgarle. ${ }^{23}$

B. La característica de universalidad no se opone a la de historicidad, no son contradictorias ni opuestas, sino complementarias.

La historicidad se refiere a tres aspectos diversos: a) la evolución de la civilización; b) nuevos problemas, necesidades y retos, y c) el contexto social y cultural de cada país.

a) El reconocimiento de los derechos humanos y de su contenido es, en buena parte, resultado de la historia universal y de la civilización y, en consecuencia, sujeto a evolución y modificación.

Recuérdese que en la cuna de la civilización occidental: Grecia y Roma, se veía con naturalidad, con algunas excepciones, la existencia de la esclavitud, individuos que eran tratados como cosas y no como personas. La esclavitud en el mundo occidental subsistió hasta después de mediados del siglo XIX, y aun en la actualidad en muchos "países civilizados" existen nuevas formas de esclavitud como la trata de personas y el trabajo forzado. No ahondo en estos problemas, sólo asiento que hay que acordarse de Hobbes: el hombre es el lobo del hombre. De aquí la importancia singular de los derechos humanos como el mejor escudo y defensa ante tales realidades y atrocidades.

Asimismo, las declaraciones de derechos humanos y su protección no nacen simultáneamente, sino por etapas, las cuales son primordialmente cuatro: a) la primera se inicia con la era moderna y la presencia de la burguesía, creándose diversas declaraciones como las americanas y francesas del siglo XVIII, con las que se precisaron derechos civiles y políticos de carácter individualista y liberal; b) la segunda tiene lugar antes, durante y

refuta, pp. 408-418; véase Bidart Campos, Germán J., op. cit., pp. 34 y 35.

${ }^{23}$ Cassin, René, "El problema de la realización efectiva de los derechos humanos en la sociedad universal", en Herrendorf, Daniel L. (comp.), Teoría general y política de los derechos humanos, México, Comisión Nacional de Derechos Humanos, 1992, p. 187. 
después de la Primera Guerra Mundial, con la consagración de los derechos sociales y económicos. Las primeras Constituciones que los reconocieron fueron la mexicana de 1917 y la alemana de 1919; c) la tercera se origina poco antes, durante y especialmente después de la Segunda Guerra Mundial, como consecuencia de los horrores cometidos durante ese conflicto, y que impulsa la universalización e internacionalización de los derechos humanos, etapa en la cual nos encontramos y que aún dista mucho de haberse perfeccionado, aunque los avances son enormes, y d) la cuarta se empalma en los últimos años con la anterior: la precisión de los derechos de solidaridad o de la tercera generación. ${ }^{24}$

b) El segundo aspecto: se precisan derechos por la existencia de necesidades que con anterioridad no existían o protegerlos no revestía mayor importancia. Por ejemplo, es claro que el derecho a la intimidad y privacidad adquiere un significado diferente con la aparición del telégrafo y el teléfono, más aún con los nuevos medios electrónicos de comunicación como el internet, y ni que decir de un medio ambiente sano y ecológicamente equilibrado o del derecho al agua. Hasta hace algunas décadas, ésos no eran problemas o no presentaban la gravedad que en la actualidad tienen en muy diversos países, y varios de esos problemas afectan al mundo entero como el grave cambio climático, y con la amenaza de que si no se toman las medidas necesarias y urgentes, la afectación de derechos puede volverse crítica para la gran mayoría de la población mundial. Un último ejemplo, los derechos de la tercera edad, que cada día son más importantes, en cuanto la expectativa de vida ha aumentado en las últimas décadas en forma impresionante en los países desarrollados y en muchos en vía de desarrollo, y que impacta en el asunto de las pensiones, los sistemas de salud y en tratar de que esos sectores poblacionales no vean afectada su calidad de vida. ${ }^{25}$

c) El tercer aspecto: el contexto social y cultural de cada país. No es posible que el Constituyente de un Estado desconozca la evolución política del mismo, su contexto cultural, sus realidades, las relaciones individuosociedad, las peculiaridades de esa nación, como por ejemplo si tiene una integración plurinacional o pluricultural. Existe un margen de discrecionalidad y de ajustes al reconocer los derechos humanos en una Constitución o

24 Carpizo, Jorge, Derechos humanos y ombudsman, México, Porrúa-UNAM, Instituto de Investigaciones Jurídicas, 2008, pp. 101 y 102.

25 Carpizo, Jorge, Temas constitucionales, México, Porrúa-UNAM, Instituto de Investigaciones Jurídicas, 2003, pp. 237 y 238. 
ley, siempre y cuando no se violen los derechos universalmente reconocidos y los cuales el Estado está obligado a respetar por medio de tratados internacionales que ha ratificado o por el jus cogens. Por ejemplo, es absolutamente inadmisible la práctica de la mutilación de los genitales femeninos en muchos países islámicos o, para no ir tan lejos, el trato discriminatorio y denigratorio que sufren las mujeres indígenas mexicanas en muchas de sus comunidades. En estos casos no se pueden alegar costumbres, usos o aspectos culturales.

Asimismo, en México no puede desconocerse la historia y olvidar los siglos, situación que continúa aunque en forma diferente, en que la Iglesia católica ha subordinado, o intentado hacerlo, al Estado mexicano. En varias de las guerras extranjeras o internas que México ha librado, la Iglesia católica se ha puesto en contra de los intereses nacionales.

Una cuestión actual que se discute con pasión en muchos países es el derecho de la mujer al aborto: ¿en cuáles situaciones?, ¿con qué condiciones?, ¿en qué supuestos? o ¿en ningún caso? En la actualidad, el Estado tiene un margen de decisión, aunque es un asunto que ya va encontrando algunos consensos internacionales mediante la ONU y sus organismos especializados. ${ }^{26}$

C. La característica de la progresividad implica que su concepción y protección nacional, regional e internacional se va ampliando irreversiblemente, tanto en lo que se refiere al número y contenido de ellos como a la eficacia de su control. Es la idea que René Cassin expresó como la impresionante expansión del concepto y de su contenido. ${ }^{27}$

A su vez, esta característica implica la irreversibilidad de los derechos. Una vez reconocidos no es posible desconocerlos. No hay un hacia atrás.

La progresividad permite que se incorporen nuevos derechos humanos a la Constitución, que se precisen y amplíen los ya reconocidos, que se eliminen o atemperen limitaciones, que se establezcan nuevas prohibiciones o límites al legislador, que se creen nuevas garantías procesales para su protección o se perfeccionen las existentes, que se ratifiquen instrumentos internacionales que amplían la defensa de los derechos, pero una vez reconocidos, tal acción es irreversible porque, como con toda precisión se ha asentado, sería un contrasentido, un absurdo que "lo que hoy se reconoce

26 Carpizo, Jorge y Valadés, Diego, op. cit., pp. 57-68.

27 Cassin, René, "Les droits de l'homme", Recueil des Cours, Leyden, Holanda, Academie de Droit International, 1974, vol. 140, p. 326. 
como un atributo inherente a la persona, mañana pudiera dejar de serlo por una decisión gubernamental". ${ }^{28}$

Esta característica está relacionada con la fuerza expansiva de los derechos humanos, lo que significa que el intérprete - generalmente, pero no sólo, el juez- debe llevar su aplicación y determinación a su máxima expresión. ${ }^{29}$

Asimismo, existen derechos que se van reconociendo y defendiendo en forma progresiva como acontece con algunos de los derechos sociales y económicos, debido a que para poder satisfacerlos, en muchos casos, es necesario que existan los recursos materiales para dicho fin. Empero, esta cuestión es más compleja que esa simple afirmación.

D. El aspecto protector estriba en que se ampara a toda persona humana, en virtud de que hasta el más poderoso puede llegar a necesitarlo, incluso se ha llegado a sostener que los derechos humanos no deben proteger sólo a la persona sino también a la comunidad nacional; sociológica y políticamente a toda la nación. ${ }^{30}$

Es cierto, pero hay que tener presente que los derechos se han ganado y han sido reconocidos a la fuerza, por medio de combates violentos. Los poderosos siempre han intentado impedir que las grandes masas hagan valer lo que les corresponde. Es un hecho histórico. El logro de ese reconocimiento de derechos ha intentado aminorar las constantes históricas de la ley del más fuerte o del pez grande que se come al chico. Entonces, no existe duda alguna que el carácter protector es fundamentalmente para el más débil.

Luigi Ferrajoli lo expresa con hermosa precisión:

De hecho, puede afirmarse que, históricamente, todos los derechos fundamentales han sido sancionados, en las diversas cartas constitucionales, como resultado de luchas o revoluciones que, en diferentes momentos, han rasgado el velo de normalidad y naturalidad que ocultaba una opresión o discriminación precedente: desde la libertad de conciencia a las otras libertades fundamentales, desde los derechos políticos a los derechos de los trabajadores, desde los derechos de las mujeres a los derechos sociales. Estos derechos

28 Nikken, Pedro, "El derecho internacional de los derechos humanos", en Revista de la Facultad de Ciencias Jurídicas y Políticas de la Universidad Central de Venezuela, Caracas, 1989, núm. 72, p. 44; del mismo autor, En defensa de la persona humana, Caracas, Editorial Jurídica Venezolana, 1988, p. 32; Nogueira Alcalá, Humberto, op. cit., pp. 58 y 71; Carpizo, Jorge, op. cit., p. 61; Sagüés, Néstor P., op. cit., p. 31.

29 Carpizo, Enrique, Derechos fundamentales y la interpretación constitucional. La Corte y los derechos, México, Porrúa, 2009, p. 110.

30 Ortecho Villena, Víctor Julio, op. cit., p. 15. 
han sido siempre conquistados como otras tantas formas de tutela en defensa de sujetos más débiles, contra la ley del más fuerte -iglesias, soberanos, mayorías, aparatos policiales o judiciales, empleadores, potestades paternas o maritales - que regía en su ausencia. Y han correspondido, en cada uno de estos momentos, a un contrapoder, esto es, a la negación o a la limitación de poderes, de otro modo absolutos, a través de la estipulación de un 'nunca más' pronunciado ante su violencia y arbitrariedad... ${ }^{31}$

E. La característica de indivisibilidad implica que todos los derechos, ya sean civiles, políticos, económicos, sociales, culturales o de solidaridad forman una unidad. Desde luego que no se puede conducir una existencia humana si se carece de libertad, igualdad y seguridad jurídica, pero éstas no son suficientes si no se cuenta con un nivel adecuado de satisfactores económicos, sociales y culturales, y será muy difícil disfrutar de esos derechos si el país enfrenta una guerra civil o externa. Entonces, resulta claro que los derechos humanos son interdependientes entre sí, que unos se apoyan en los otros para integrar la mencionada unidad o bloque.

La característica de la indivisibilidad es diversa del asunto de si todos los derechos tienen la misma jerarquía. Sin entrar a mayor discusión, es claro que el derecho a la vida guarda mayor importancia que muchos otros, como puede ser la inviolabilidad de la correspondencia o la libertad de tránsito. Sin vida los demás derechos pierden cualquier valor para la persona.

También debe decirse que una Constitución puede expresamente señalar la jerarquía superior de algunos derechos, o implícitamente al enumerar aquellos que no pueden suspenderse en ningún caso, ni en el de una grave emergencia.

F. La característica de eficacia directa significa que los derechos humanos reconocidos en la Constitución y en los instrumentos internacionales ratificados por un país vinculan obligatoriamente a todos los poderes públicos -Ejecutivo, Legislativo, Judicial y Órganos Constitucionales Autónomos-, así como a autoridades, grupos y personas, y para ello no es necesario que

31 Ferrajoli, Luigi, Los fundamentos de los derechos fundamentales, Madrid, Trotta, 2007, p. 363. Yo concuerdo con esta concepción, y también Carbonell, Miguel, op. cit., pp. 31 y 32; Silva Meza, Juan N. y Silva García, Fernando, op. cit., pp. 171 y 172; Dienheim Barriguete, Cuauhtémoc Manuel de, Constitucionalismo universal: la internacionalización y estandarización de los derechos humanos, Buenos Aires, Ad-Hoc, 2009, p. 24. 
una ley desarrolle los alcances de ese derecho humano, aun en el supuesto de que la Constitución señale la existencia de esa ley. ${ }^{32}$

Esta característica responde al principio de la jerarquía de las normas en un orden jurídico. Sería absurdo que el legislador decidiera incumplir la Constitución y los instrumentos internacionales con su simple omisión; su incumplimiento a una obligación que la propia Constitución le señala, subordinaría a ésta a la voluntad del legislativo, convirtiéndola en simple norma secundaria. Esta posibilidad real es una imposibilidad jurídica, de la que deriva la eficacia directa de los derechos humanos.

El artículo 1o., inciso 3, de la Ley Fundamental de Bonn de 1949 es precisa al respecto: "Los siguientes derechos fundamentales vinculan a los poderes Legislativo, Ejecutivo y Judicial a título de derecho directamente aplicable".

En forma indirecta, el artículo 44 de la Constitución de Perú también declara esta característica al señalar que es deber primordial del Estado garantizar la plena vigencia de los derechos humanos; en consecuencia, no pueden quedar subordinados a la expedición de una ley.

28. Todos los derechos humanos poseen las características señaladas. Así lo confirmó la sección I, párrafo 5, de la ya mencionada Declaración y Programa de Acción que procede de la Conferencia Mundial de Derechos Humanos de 1993, celebrada en Viena:

Todos los derechos humanos son universales, indivisibles e interdependientes y están relacionados entre sí. La comunidad internacional debe tratar los derechos humanos en forma global y de manera justa y equitativa, en pie de igualdad y dándoles a todos el mismo peso. Debe tenerse en cuenta la importancia de las particularidades nacionales y regionales, así como los diversos patrimonios históricos, culturales y religiosos, pero los Estados tienen el deber, sean cuales fueren sus sistemas políticos, económicos y culturales, de promover y proteger todos los derechos humanos y las libertades fundamentales.

No coincido únicamente en que todos los derechos humanos son iguales. En principio así es, pero existen unas cuantas excepciones. Ya señalé la más importante, el derecho a la vida, tema al que aludo en el siguiente numeral.

La mencionada reforma constitucional de junio de 2011 decidió incorporar algunas características de los derechos humanos en el artículo 1o. de

32 Nogueira Alcalá, Humberto, op. cit., pp. 58 y 72; Ortecho Villena, Víctor Julio, op.cit., p. 16. 
nuestra Constitución: los principios de universalidad, interdependencia, indivisibilidad y progresividad. Las que omitió, asimismo, forman parte inseparable de la naturaleza de los derechos humanos.

\section{LA ARMONIZACIÓN DE LOS DERECHOS HUMANOS}

29. Una cuestión discutida es si entre los derechos humanos existen conflictos o contradicciones y, si tal es el caso, cómo se resuelven o se pueden superar.

Considero que, en virtud de la naturaleza de los derechos humanos y sus características, temas que he abordado en este ensayo, entre los diversos derechos humanos no puede existir conflicto alguno ni enfrentamiento, sino armonía y compatibilidad, las que deben precisar las Constituciones, los tratados internacionales, las leyes y las tesis jurisprudenciales. La doctrina otorga elementos para lograr dicha armonía y compatibilidad.

¿Y por qué es indispensable que se realice dicha armonía y compatibilidad? Por una razón sencilla, pero extraordinariamente importante: para no vulnerar, infringir o anular los derechos y libertades de otra u otras personas, porque los derechos y libertades son para todas y de todas, para y de cada persona y ser humano.

Es la idea que Emmanuel Kant expresó al manifestar que la libertad de cada uno no debe ser restringida más allá de lo que es necesario para asegurar una libertad igual a todos. $\mathrm{O}$, en otras palabras, es el mismo pensamiento de Karl Popper al afirmar que la paradoja de la libertad ilimitada es que ella conduce a la dominación del más fuerte. ${ }^{33}$

Estas ideas están incorporadas en textos legales. Por ejemplo, el artículo 32.2 de la Convención Americana sobre Derechos Humanos dice: "Los derechos de cada persona están limitados por los derechos de los demás, por la seguridad de todos y por las justas exigencias del bien común, en una sociedad democrática".

Debo precisar que la tesis de la armonía o armonización de los derechos humanos no es universalmente admitida. No obstante, si se examinan con cuidado los pensamientos de autores que hablan de colisiones, conflictos o enfrentamientos entre ellos, veremos que pareciera que algunos tímidamente

33 Pigeat, Henri, Médias et déontologie. Règles du jeu ou jeu sans règles, París, Presses Universitaires de France, 1997, pp. 7 y 8. 
se van acercando a la idea de su necesaria armonización o delimitación de unos con los otros. ${ }^{34}$

Eduardo Novoa afirma que resulta casi contradictorio - y así me parece- suponer que dos o más derechos humanos puedan entrar en colisión o pugna entre sí, sin embargo se dan situaciones en que la vida privada de una persona "choca" con la necesidad de otras de poseer una mayor información sobre lo que acontece en la vida social. Es decir, de acuerdo con su pensamiento se dan casos en los cuales el derecho a la vida privada se presenta como "opuesto" a la libertad de información, a la cual tienen derecho los demás miembros de la sociedad. ${ }^{35}$

Desde luego, las tesis que se inclinan por las colisiones, conflictos o enfrentamientos entre los derechos humanos encuentran aparentemente un indiscutible ejemplo de ello en la relación que se establece entre el derecho a la vida privada y el derecho a la información, y es que si la cuestión no se examina con cuidado sí pareciera que existe ese conflicto, pero si nos auxiliamos con la lupa de las ideas anteriormente expuestas, veremos que ese aparente conflicto es sólo un asunto de armonización de derechos, y desde esta perspectiva no existe jerarquía superior entre los derechos a la vida privada y a la información, sino que examinándose el caso concreto, el juez decide qué precepto constitucional y legal debe aplicar a dicho asunto. El juez, sin embargo, debe respetar el marco constitucional y legal que armoniza los diversos derechos humanos.

34 El distinguido tratadista español González Pérez, Jesús, La degradación del derecho al honor (honor y libertad de información), Madrid, Cuadernos Civitas, 1993, pp. 37-39, sostiene lo siguiente: "El ejercicio de un derecho fundamental puede dar lugar a colisiones con otros derechos que la Constitución consagra asimismo como fundamentales, que es necesario resolver salvando en lo posible el contenido esencial de cada derecho. Es indudable que el contenido esencial de un derecho - contenido que en todo caso debe respetar su regulación, según el artículo 53.1 de la Constitución-impone límites a su ejercicio, en cuanto no puede amparar actuaciones que vayan más allá de aquél. Se trata de límites intrínsecos del derecho, distintos a los que pueden venir del ejercicio de otro con el que se entra en colisión. Estamos ante un problema de delimitación y no de limitación.

Cuando el ejercicio de un derecho fundamental dentro de su ámbito propio incide en el ámbito de otro es cuando se produce una colisión, que habrá de resolverse tratando de respetar al máximo el contenido esencial de cada uno y, en tanto no sea posible, dando primacía a uno de ellos. La prioridad puede venir expresamente establecida en el propio texto constitucional".

35 Novoa Monreal, Eduardo, Derecho a la vida privada y libertad de información, México, Siglo Veintiuno Editores, 1981, p. 9. 
30. Establecer con claridad que no existe conflicto o pugna entre los derechos humanos reviste una importancia singular para su comprensión y su protección efectiva. Por esta razón, profundizo un poco más en el ejemplo que señaló Eduardo Novoa, y porque el mismo es muy socorrido para pretender demostrar el punto de vista contrario al que sostengo.

La Suprema Corte argentina, en un juicio connotado - el de "Campillay"-, asentó en 1986 que la libertad de expresión es la libertad de dar y recibir información, pero que éstas no implican un derecho absoluto, y el legislador, ante los posibles abusos producidos mediante su ejercicio, tipifica diversos delitos penales y establece ilícitos civiles, ya que "el ejercicio del derecho de informar no puede extenderse en detrimento de la necesaria armonía con los restantes derechos constitucionales, entre los que se encuentran el de la integridad moral y el honor de las personas (artículos 14 y 35 , Constitución nacional)". ${ }^{36}$

En esta sentencia, la tesis de la armonía de los derechos humanos es muy clara y se encuentra dentro de las grandes corrientes del humanismo occidental. Empero, también se ha considerado que la Suprema Corte argentina en otras resoluciones ha limitado la libertad de prensa para otorgar jerarquía prioritaria al derecho al honor y a la dignidad personal. ${ }^{37}$

Yo no haría el planteamiento de esa manera, porque vulnera la esencia de la tesis de la "armonización". Entre los derechos humanos no existen jerarquías, con la única excepción de los derechos no derogables, como son, entre otros, el derecho a la vida, la prohibición a la esclavitud y la prohibición de la tortura y tratos inhumanos. ${ }^{38}$

Lo que acontece, vuelvo a expresarlo, es que el juez aplica los preceptos constitucionales y legales, incluyendo las "limitaciones" a esos derechos, al caso concreto, armonizando dos derechos humanos: en este caso específico el de la vida privada y el de la libertad de expresión o derecho a la información en su acepción actual.

${ }^{36}$ Citado por Zannoni, Eduardo A. y Bíscaro, Beatriz R., Responsabilidad de los medios de prensa, Buenos Aires, Astrea, 1993, p. 50.

37 Bidart Campos, Germán José, "La evolución constitucional en Argentina entre 1917 y 1987”, El Constitucionalismo en las postrimerías del siglo XX, México, UNAM, 1988, t. III, p. 63.

38 Gómez-Robledo, Alonso, "Protección de la 'privacía' frente al Estado", Diagnóstico genético y derechos humanos. Cuadernos del núcleo de estudios interdisciplinarios en salud y derechos humanos, México, UNAM, 1998, pp. 92 y 93. 
Miguel Urabayen sostiene que entre los derechos a la intimidad y a la información hay que encontrar un equilibrio, porque ambos son de esencial y equivalente importancia, pero de no ponérseles límites, cada uno tratará de anular al otro. De inmediato agrega que como el interés general priva sobre el particular, "podría partirse de la base de que el derecho a la información es la regla y el derecho a la intimidad la excepción". Termina afirmando que hay que examinar cada caso planteado, que es lo que sostengo. ${ }^{39}$

El juez analiza el caso que se ha sometido a su consideración y armoniza - equilibra, diría Urabayen - las normas aplicables para que la justicia se realice en el caso concreto, pero sin que uno de esos derechos humanos tenga mayor jerarquía que el otro. El problema - reitero- se circunscribe a decidir cuáles son las normas aplicables a esa causa determinada. Esta labor no es fácil, porque implica la utilización de conocimientos profundos del orden constitucional, así como de sus técnicas de aplicación e interpretación.

Zannoni y Bíscaro se refieren a los límites internos de la libertad de expresión — la verdad y la actitud del informador hacia la verdad - y a los externos: el establecimiento de adecuados equilibrios si se suscita un "conflicto" con otro u otros derechos fundamentales, como puede acontecer en el caso del derecho a la privacidad o intimidad, que posee igual excelencia y jerarquía formal que aquél. Estos autores precisan que los derechos fundamentales no prevalecen unos sobre los otros, como principio a priori. ${ }^{40}$

Alonso Gómez-Robledo destaca que la protección de la vida privada es igualmente un criterio determinante del carácter democrático de toda la sociedad, o sea que ella es condición y garantía de todo régimen democrático. A Gómez-Robledo le asiste la razón. ${ }^{41}$ Los países donde la democracia funciona mejor son aquellos donde existe mayor preocupación por proteger

39 Urabayen, Miguel, Vida privada e información: un conflicto permanente, Pamplona, Ediciones Universidad de Navarra, 1977, p. 349.

40 Zannoni, Eduardo A. y Bíscaro, Beatriz R., op. cit., pp. 63, 64, 88 y 89.

41 Gómez-Robledo, Alonso, op. cit., pp. 90, 100 y 101, hace una precisa síntesis sobre la armonización del derecho a la protección de la vida privada y el derecho a la información; al respecto asienta:

"Si la libertad de expresión es sin duda un fundamento esencial de todo orden democrático, es igualmente cierto que la protección de la vida privada es garantía y condición de la vida democrática.

En principio, la publicación de informaciones no debería ser obstaculizada en forma alguna; sin embargo, debe hacerse la distinción entre información verídica y falsa noticia. La prohibición de informaciones falsas no es contraria a la exigencia de la libertad. La posibilidad de limitar la libertad de publicar informaciones, incluso fidedignas, 
la vida privada. En contraste, en los regímenes totalitarios esta protección casi o de plano desaparece. Recuérdese la obra 1984 de George Orwell. Éste es el peligro real cuando desaparecen o se deterioran las protecciones a la vida privada: el ser humano pasa a la categoría de cosa, su dignidad se va deteriorando hasta ser pulverizada. Entonces ¿de qué serviría la libertad a la información para seres autómatas privados de lo más importante que se posee que es la dignidad humana?

Confío en que con este importante ejemplo quede clara la tesis de la armonización y compatibilidad entre los derechos humanos.

está vinculada a la existencia de otras libertades, y la libertad de información ejercida en forma dolosa pone en riesgo grave las otras libertades.

La libertad de la persona, el respeto debido a la vida privada, son protegidos por la ley penal contra los abusos de la información. Esta protección queda generalmente asegurada por el régimen jurídico de la difamación.

Las necesidades de una buena administración de justicia y la salvaguarda de los derechos de la defensa, conducen igualmente a prohibir la publicación de ciertas informaciones".

Fecha de recepción: 15 de mayo de 2011.

Fecha de dictamen: 15 de junio de 2011. 